\title{
Environmental Forces underneath the Innovativeness of Manufacturing Firms
}

\author{
Jeffrey Yi-Lin Forrest ${ }^{1}$, Canchu Lin ${ }^{2}$, Sunita Mondal1, Reginald Tucker ${ }^{3}$ \\ ${ }^{1}$ School of Business, Slippery Rock University, Slippery Rock, PA, USA \\ ${ }^{2}$ School of Business, Carroll University, Waukesha, WI, USA \\ ${ }^{3}$ Stephenson Department of Entrepreneurship and Information Systems, Louisiana State University, Baton Rouge, LA, USA \\ Email: Jeffrey forrest@sru.edu, sunita.mondal@sru.edu,clin@carrollu.edu,regtucker@lsu.edu
}

How to cite this paper: Forrest, J.Y.-L. Lin, C.C., Mondal, S. and Tucker, R. (2019) Environmental Forces underneath the Innovativeness of Manufacturing Firm. Theoretical Economics Letters, 9, 1353-1382. https://doi.org/10.4236/tel.2019.95088

Received: April 8, 2019

Accepted: June 11, 2019

Published: June 14, 2019

Copyright (c) 2019 by author(s) and Scientific Research Publishing Inc. This work is licensed under the Creative Commons Attribution International License (CC BY 4.0).

http://creativecommons.org/licenses/by/4.0/

\section{(c) (i) Open Access}

\begin{abstract}
This paper examines holistically how the competitive dynamics of the market invites and stimulates manufacturing firms to take innovative actions and which of the nearly twenty environmental factors empirically identified in the literature actually dominates the firms' innovation. After developing a general definition of innovation in the manufacturing sector, two main results are established with the thinking logic of systems science and the rigor of game theory. One result is on when the market signals its invitation for innovation; and the second result is about why innovation is the only way for firms' survival. By using these results and the systemic yoyo model, we identify four dominating environmental determinants on innovation of manufacturing firms-demand growth, proximity, networking, and government and public sector policies. Our results allow us to offer both theoretical and practical implications for managers and policy makers.
\end{abstract}

\section{Keywords}

Consumer Loyalty, Market Invitation, Nash Equilibrium, Systems Thinking, Yoyo Model

\section{Introduction}

This paper addresses two important questions concerning manufacturing and innovation. First, what does innovation in the manufacturing sector mean? Second, what environmental determinants and market conditions exert dominating effects on innovation in manufacturing firms? These problems have been important in practice for managers, intriguing in theory for scholars, and challenging in economic development for policy makers, because the business world 
has been evolving faster and faster than ever before so that decision makers have less time to analyze what is happening [1]. Hence, they have to focus their attention on the dominating determinants, which tend to be only a few instead of many that are generally beyond the human ability to comprehend holistically, in order to introduce appropriate action plans within a limited amount of time.

As early as in 1776, Adam Smith recognized in his monumental work, The Wealth of Nations, the importance of innovation as a crucial economic activity that fosters wealth. However, the topic of innovation had not been systematically studied until the beginning of the $20^{\text {th }}$ century when Joseph Schumpeter [2] published his book, entitled "The Theory of Economic Development", where he claims that innovation represents the driving force of economic development. The two questions raised earlier are of increasing importance considering the era of transient competitive advantages the current business world is in and intense global competition [1]. Innovation, be it about products, managerial operations or production processes, represents a fundamental principle under each and every competitive advantage. This explains why innovation is now inescapable for firms and business organizations that desire to successfully ride waves of transient competitive advantages, expand their existing territories, and gain entry into new markets [3] [4] [5] [6].

Because of its theoretical and practical importance, innovation has gained a tremendous amount of scholarly attention in recent decades. However, the majority of published studies that examined innovation took an empirical approach using various methods of data mining and presenting mixed conclusions, ranging from positive correlations between the various sets of determinants of innovation and the innovativeness of manufacturing firms, to neutral and to negative. That makes it difficult for innovation to be prescribed in practice [7] [8]. Additionally, in testing various explanatory variables for their effects on innovation in the manufacturing sector, extant studies found that these variables are correlated with innovation in varying degrees [9] [10] [11]. While the findings from the past studies are illuminating for our understanding of innovation, they are piecemeal in nature. More specifically, most of these empirical studies focused on a few variables but ignored others because of the limitations in their research design. Further, past research mostly offered us an understanding of innovation based on empirical observations which have not assisted scholars in prescribing practical applications, making our knowledge of innovation incomplete and unsystematic [12]. To fill this void, there emerges a need to address and investigate innovation from a systemic perspective.

Considering where we are in the understanding of innovation and what challenges exist in this area of research, this paper aims to develop a sound theory based on the essence of systems science and game theory on innovations in the manufacturing sector. The purpose of this paper is to identify the dominating environmental determinants on innovation among a set of nearly twenty variables recognized by various scholars in the last three some decades from the angle of the dynamics of market competition. Our aim is to contribute to the 
current conversation by examining innovation in the manufacturing sector and what key environmental factors exert forces on innovative activities and processes in manufacturing firms.

Another important contribution of this work is the introduction and application of symbolic reasoning, systems science (especially, the systemic yoyo model), and game theory to the study of innovation. Although methods of data mining help uncover potential facts, the literature [7] [13] shows that for the most part these methods only lead to mixed results. That is, more advanced methods of expression and reasoning need to be mobilized in order to unify the previously established results, although mostly mixed, into an organic whole that is capable of producing specifiable, predictable, and repeatable recommendations for practical purposes.

The rest of this paper is organized as follows. Section 2 provides a brief summary of the rapidly growing literature on innovation in manufacturing sector. Section 3 establishes a general concept of innovation in manufacturing sector. Section 4 presents the main results of this work: following an introduction to the basics of systems science, the section shows how the market could signal its invitation for innovation and how the market could stimulate innovation. With these main results in place Section 5 analyzes holistically all the environmental determinants of innovation, as studied by various scholars in the past, and identify those determinants that actually dominate the occurrence of innovation in the manufacturing sector. Section 6 concludes the paper with managerial and policy decision making implications and open questions for future research.

\section{Innovation in Manufacturing Sector: An Active Field of Study}

The importance of innovation has been recognized since at least the time of Adam Smith [14] when he states that innovation is a crucial economic activity to fostering wealth. The topic of innovation in the manufacturing sector represents a traditional field of study [15] with innovativeness closely related to the prosperity of manufacturing firms [16] as well as a critical factor for the firms' survival and growth [17] [18]. In practice, innovation is mainly materialized through introducing original products and processes [7] that enable manufacturing firms to competitively enter or create new markets [19].

Many scholars have treated innovation as one major factor of long-term success [20]. This part of the literature investigates administrative innovations and organizational processes accompanying technical developments [21] [22], the innovation of products and processes [23] and incremental and radical innovations [24] [25].

In the manufacturing sector, Veugelers and Cassiman [26] examine innovation strategies. They find that high perceived risks and costs and low appropriation do not discourage innovation, but rather determines how the innovation sourcing strategy is chosen. Their results suggest that small firms are more likely to restrict their innovation strategy to an exclusive make or buy strategy, while 
large firms are more likely to combine both internal and external knowledge acquisition in their innovation strategy. Amara and Landry [27] study how sources of information play a role on the novelty of innovation by considering four categories of sources of information-internal sources, market sources, research sources, and generally available sources-which firms use to develop or improve their products or manufacturing processes. They find that manufacturing firms prefer to use a large variety of research sources to develop or improve their products or processes so that the novelty of innovation could be increased in encouraging connections between firms, government laboratories and universities.

Product and process innovation also plays fundamental roles in manufacturing firms. Becheikh et al. [7] demonstrate that these two types of innovations are closely associated to the manufacturing environment with product innovation receiving more attention from scholars and managers. As for innovation for competition, Nieto and Santamaria [28] investigate the critical factors behind novel product innovations by stressing the role of diverse types of collaborative networks in reaching product innovations and their degree of novelty. They show that strong collaborations with suppliers, clients, and research organizations have a positive impact on the novelty of innovation, while collaboration with competitors has a negative impact. This logic also extends to family firms. De Massis et al. [29] show that family businesses are different from nonfamily firms in product innovation strategies and the organization of innovation processes. In particular, they find that manufacturing family firms focus on incremental product innovations by using more external sources, while nonfamily firms more on breakthrough and radical innovation through a predominantly closed approach. And, family firms are more risk-averse in their decisions about product innovation, while nonfamily organizations tend to embrace major risk taking.

Innovation and organizational learning are closely related. For example, Alegre and Chiva [30] study how organizational learning capability affects product innovation performance by developing a model of 5-dimensions-experimentation, risk taking, interaction with the external environment, dialogue, and participative decision making. Considering the emerging market demand, Lin et al. [31] explore the increasing importance of green products and if and how green product innovation can affect firm performance. They show that market demand is positively correlated to both green product innovation and firm performance, and leads manufacturing firms to a better performance through a continuous innovation process.

With the recent economic globalization and the advent of internet-based technologies, the environment of manufacturing has changed drastically; manufacturing firms have experienced increasing pressures to be more competitive and innovative than ever before [32] [33] [34]. That has led to the emergence of new manufacturing philosophies, such as remote manufacturing, computer-integrated manufacturing systems, Internet-based manufacturing and more 
[32] [35]. These new philosophies have redefined the concept of manufacturing and innovation in the manufacturing field [36] [37]. The most famous ones are Industry 4.0 and China's manufacturing 2025, where cyber-physical systems are employed to monitor and synchronize physical factory and cyber computational space [38] [39].

\section{The Concept of Innovation in Manufacturing Sector}

Schumpeter [2] claims that innovation represents the driving force of economic development. It also represents one of the main factors underlying countries' international competitiveness and their productivity, output and employment performance [40] [41]. More specifically, Schumpeter [2] discusses the concept of innovation within the context of a firm by delineating its extent as product, process, and business model, by focusing on the role of economic factors in technical advancement and by recognizing that economic development is a "creative destruction" that is characterized by quick turnovers of established monopolies by catching-up newcomers. Later, Schumpeter [42] referenced the concept of innovation processes without providing any explanation for how innovations come about. The importance of Schumpeter's works is manifested by the emergence of an extensive literature of empirical evidence on innovation [43] [44] [45]. Such literature provides an important source of information for companies that either desire to develop a competitive advantage or gain entry into new markets [3] [4] [46].

The concept of innovation (in the manufacturing field) can be formulated by looking at diverse aspects of invention, such as its necessity and sufficiency [47], intentionality [48], beneficial nature [49], practical implementation [50], and its diffusion [51]. Considering the fact that innovation is a wide-ranging, multifaceted phenomenon, several definitions of innovation are introduced in the literature. For example, OEDC [4] maintains that:

Innovation is an activity that encompasses all the scientific, technological, organizational, financial, and commercial activities essential to the creation, implementation, and marketing of new or improved products or processes.

Becheikh et al. [7] define an innovation as (Having) implemented technologically new products and processes and (produced) significant technological improvements in products and processes, where these authors only focus on such technological innovations that are related to products and processes, a technologically new product/process or a product/process that has undergone a significant technological improvement, and that it has been implemented, introduced into the market (product innovations) or used in a production process (process innovations). And, Crossman and Apaydin ([52] p. 1155) define the concept of innovation as.

The production or adoption, assimilation, and exploitation of a value-added novelty in economic and social spheres; renewal and enlargement of products, services, and markets; development of new methods of production; and establishment of new management systems. 
For our purpose of this paper, all the listed versions of the definition of innovation seem to be too narrowly stated in one way or another, because as Industry 4.0 and China's manufacturing 2025 unfold in front of our very eyes, newer particulars will most likely need to be added and stressed. Hence, let us define innovation in manufacturing sector as follows with an attempt of capturing all the vital essences of the concept:

Innovation in the manufacturing sector is such a set of activities-which could be just one particular activity or several - that leads to exceptionally added value to the company when compared to other activities that take place in the same sector.

Implicitly, because of its abstraction and emphasis on the comparatively added value, this definition of innovation implies many facets of the concept. For example, the generation of exceptionally added value implies that 1) an extraordinary level and/or quality of creativity has to be involved over time; 2) the creativity has to be both internally conceived, driven either by the current needs or forecasted future demands, and externally adopted, such as market acceptance; 3) relevant new processes have to be designed and introduced in order to develop and push products onto the market to realize the said value; 4) intended benefits are materialized; 5) other than inventions this definition also emphasizes on the translation of inventions into marketable new or improved products or processes; 6) the definition leaves open the possibility of relative newness; and 7) although not particularly mentioned, the definition includes potential roles of relevant processes and outcomes.

Note that this definition excludes those activities or innovations that only keep the companies afloat when compared to others in the same industries. In other words, the urge for a manufacturing firm to innovate is mainly from within the organization instead of purely from pressures of the needs of survival and fending off competitions. As a matter of fact, such an urge needs to be expressed in the mission statement of the company [53]. For example, in the rivalry between Eastman Kodak and Fuji Films, Kodak identified and invested in resources and capabilities and took actions against what Fuji Films was doing in order to fence off the competition of the latter. However, its efforts of innovation led Kodak to a wrong direction. That explains why Kodak has since become a company no longer relevant in the market place [1], and why our condition of exceptionally added value is important in defining what innovation in manufacturing sector is.

Our definition of innovation in the manufacturing sector assists in drawing a parallelism between the study of disaster predictions and that of innovation. The reason why an event becomes a disaster is because the occurrence of the event is unexpected and causes major losses [13]. Similarly, an innovation creates exceptional added value because the particular innovation is not expected to be significant by the participants of the market [54].

In the rest of this paper, any innovation addressed will be that defined lastly above for manufacturing sector. 


\section{The Main Results}

A large body of literature on technological product and process innovations has looked at what economic factors or forces would lead to innovation in the manufacturing sector from various angles that are either internal or external to the companies of concern [7]. In this section, we analyze the environmental forces identified in the literature from the height of systems science in order to sort out what the main environmental determinants are driving innovations in the manufacturing sector.

\subsection{Relevant Basics of Systems Science}

To make this paper self-contained, this subsection briefly introduces the relevant basics of systems research. Because scholars in the research area of innovation are quite familiar with game theory, all the related details are omitted.

System exists everywhere, especially in the investigations of economic issues and business decision making. For example, each person is a complex biological system, made up of many smaller systems. At the same time, she is also a member of many social and economic systems, such as a family, neighborhoods, communities, etc. And each day she interacts with a range of various systems, such as a car, an ATM machine, retail stores, the company she works for, etc. These systems interact with each other constantly. Hence, other than using numbers and variables to investigate problems and issues of business and economics, which is what is mostly done in the literature in these areas, there is a need for us to employ the concept of systems and relevant methods to study economic phenomena in order to obtain new understandings and conclusions.

Historically, the concept of systems has been directly or indirectly introduced by scholars from different disciplines. For example, in the area of economics Rostow [55] wrote in 1960 that: The classical theory of production is formulated under essentially static assumptions... to merge classical production theory with Keynesian income analysis... introduced the dynamic variables: population, technology, entrepreneurship, etc. But... do so in forms so rigid and general that their models cannot grip the essential phenomena of growth... We require a dynamic theory... which isolates not only the distribution of income between consumption, savings, and investment (and the balance of production between consumers and capital goods) but which focuses directly and in some detail on the composition of investment and on developments within particular sectors of the economy. In the area of biology von Bertalanffy in 1924 [56] points out that because the fundamental character of living things is their organization, the customary investigation of individual parts and processes cannot provide a complete explanation of the phenomenon of life. And many others, such as Porter [57], Klir [58], Lin [59], etc., also demonstrate how powerful holistic way of thinking and relevant methodology could be in terms of producing conclusions that are realistically reliable and practically usable regarding organizations. That is, business entities, economies, and markets interact with each other. As a mat- 
ter of fact, since the 1920s [56], such a holistic view of nature, organizations, and social events has permeated the entire spectrum of knowledge, see [59] and references found there for details on how specific areas of learning have benefitted.

Numbers and systems are abstracted out of the physical world from two different angles. When an organization is seen as a collection of unrelated people and properties, numbers come into play, such as $n$ employees, $m$ copy machines, etc. When the organization is seen holistically, the concept of systems emerges, where such elements as employees, capital, properties, etc., form an organic whole through various relationships, without which the organization does not exist. In other words, all studies in business related disciplines are essentially about relationships of one kind or another (or systems), be they firms, markets, industries, or economies. The major differences between numbers and systems include: 1) the former is a small scale local concept, while the latter a large-scale organizational concept [60] [61]; and 2) numbers exist only post existence, while systems emerge at the same time when physical or intellectual existence comes into being [59]. That is the reason why systems methodology is a more appropriate tool than all theories developed on numbers and variables for the investigation of economic entities when their internal structures are concerned with and why the Wall Street still cannot successfully make advanced predictions for imminent economic disasters, for more in-depth explanation see [13].

By systems science, it means the totality of all studies of various kinds of systems. In the past 90 some years, the methods of systems science have been widely employed in different disciplines [62]. Similar to how the Cartesian coordinate system-consisting of the crossing of two or more number lines-plays its role in the development of the traditional science [63], in systems science the role is played by the systemic yoyo model [64] shown in Figure 1.

Specifically, on the basis of the blown-up theory [65], a general theory of development, and the discussion on whether or not the world can be seen from the viewpoint of systems [60] [66], the concepts of black holes, big bangs, and converging and diverging eddy motions are coined together in the model shown in Figure 1 for each object and every system imaginable. That is, each system is a multi-dimensional entity that spins about its axis. If we fathom such a spinning entity in our 3-dimensional space, we have such a structure as artistically shown in Figure 1(a). The black hole side pulls in things, such as materials, information, investment, profit, etc. After funneling through the "neck", things are spit out in the form of a big bang. Some of the materials, spit out from the end of big bang, never return to the other side and some will (Figure 1(b)). Due to its general shape, such a structure is referred to as a yoyo.

What this systemic model says is that each physical or intellectual entity in the universe, be it a tangible or intangible object, a living being, an organization, a market, an economy, etc., can all be seen as a kind of realization of a certain multi-dimensional spinning yoyo with an eddy and meridian field around. It stays in a spinning motion as depicted in Figure 1(a). If it does stop its spinning, it will no longer exist as an identifiable system. What Figure 1(c) shows is that 


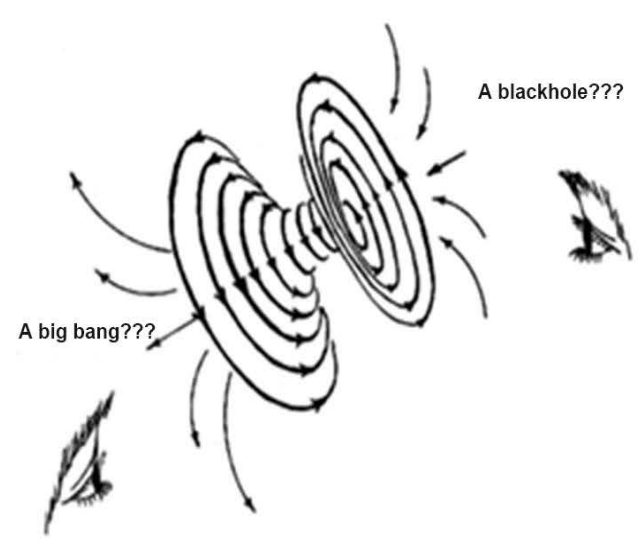

(a)

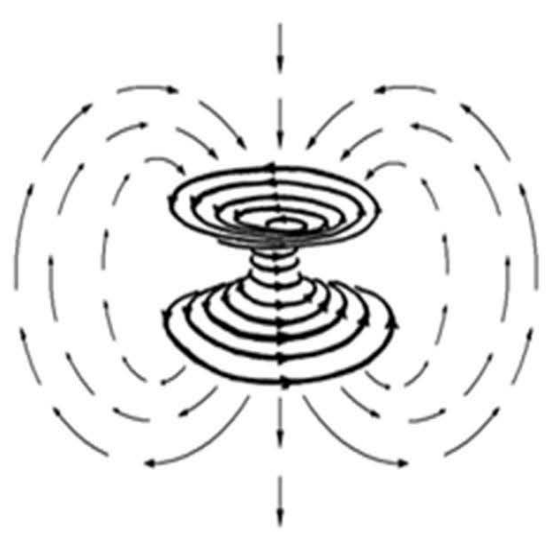

(b)

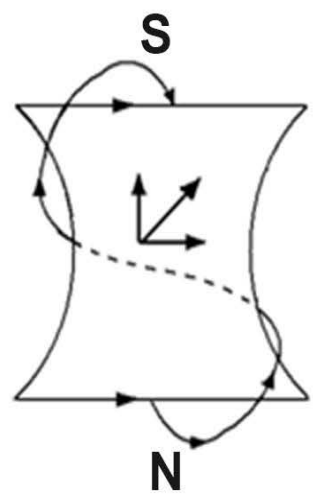

(c)

Figure 1. (a) Eddy motion model of the general system; (b) The meridian field of the yoyo model; (c) The typical trajectory of how matters return

due to the interaction between the eddy field, which spins perpendicularly to the axis of spin, of the model, and the meridian field, which rotates parallel to axis of spin, all the materials that are either new to the yoyo body or returning to the black-hole side travel along a spiral trajectory.

\subsubsection{The Systemic Structure of the Firm}

In this subsection we see how the firm can be seen systemically as an abstract spinning yoyo. In management science, it is well known that each firm has its own particular organizational culture. Differences in organizational cultures lead to varied levels of productivity. Now, the basic components of an organizational culture change over time, where some components are removed while certain others are introduced. These changes constitute the evolution of the firm and are caused by both inventing and importing ideas from other organizations and consequently modifying or eliminating some of the existing ones.

The concept of "spin" beneath the systemic yoyo structure of the firm comes from what ideas to invent, which external ideas to import, and which existing ones to modify or eliminate. For example, assume that idea A will likely make the firm more prosperous with higher levels of productivity, and that idea B will likely maintain the firm as it has been. Then these ideas will form a spin in the organizational culture. Specifically, some members of the firm, such as the junior members, might like additional productivity so that their individual goals can be materialized in the process of creating the extra productivity, while some other members, such as those who are most senior, might like to keep things as they have been so that what they have achieved, such as income, prestige, social status, etc., will not be adversely affected. These two groups will generally fight against each other to push for their respective agendas, making ideas $A$ and $B$ "spin" around each other. For one moment A is ahead; for the next moment B is leading. And at yet another moment no side is ahead when the power struggle might very well return to the initial state of the affair. In such a particular inci- 
dence, the abstract axis of spin is invisible, because no one is willing to openly admit his underlying purpose for pushing for a specific idea (either A or B or maybe other ones).

The "black hole" of the abstract systemic body in the firm stands for the inputs of the firm; and the outputs of the firm are collectively the "big bang". And when the firm is seen from different angles, the meanings of "black hole" and "big bang" are different. But, together these different "black holes" and "big bangs" make the firm alive. Without the totality of "black holes" and that of "big bangs", the firm cannot be physically standing and conceptually existing.

\subsubsection{Ocean of Eddy Motions}

Relating to what we discuss in this paper, each human organization, be it a firm, a market, or an economy, as a whole is made up of its physical body, internal structure, and its interactions with the environment. This whole, according to the systemic yoyo model, is a high dimensional spin field, where the internal structure and interactions with the outside world affect each other and change the characteristics of the physical body. Considering the body being the carrier of all other aspects of the organization, in theory the body is a pool of "fluid" realized through human sensing organs in the three-dimensional space. The word "fluid" here is an abstract term totalling the flows of information, resources, profits, investments, etc., circulating within the inside of, going into, and giving off from the body. So, each firm, each market and each economy represent an ever-evolving and constantly changing ocean of eddies, which interact with each other persistently. As a matter of fact, this end is also recognized by the contingency theory and supported by empirical evidence: Each organization is above all an adaptive system which evolves by reacting to its environment; and indeed, environment has a determining impact on firm's strategies, structuring and behaviors [67] [68] [69] [70].

We are now ready to look at the main questions this paper addresses in light of the holistic thinking just described.

\subsection{Market Invitation for Competition}

To determine how a firm is affected by the market, assume that the firm attempts to enter the market that is occupied by $m$ incumbent firms, $m=1,2, \cdots$ Assume that these incumbents provide consumers with mutually substitutable products; each of them has developed its respective share of loyal consumers who purchase the products from their respective firms only as long as the price is not more than their reservation price, which is set to be 1 . At the same time, assume that there is a market segment of consumers who switch from the product of one firm to another depending on whose price is more competitive. This situation commonly occurs either when the market is expanding or when numerous new firms enter the market due to the entry barrier being lowered by new technologies. Hence, the incumbent firms compete over the switchers with 
adjustable prices charged to their consumers. By doing so these firms hope they could not only protect their existing turfs, but also deter the potential entrance of new competitions [71].

Assume that the incumbent firms produce their horizontally differentiated products at constant marginal costs, which are set to zero without loss of generality. Assume additionally that the managements of these $m$ firms are well aware of the pricing strategies of the other firms and have established their best responses by playing the Nash equilibrium through pure self-analyses. In other words, what is assumed implies that the market is in a state of mutual forbearance, where incumbent firms mitigate rivalry by dividing up the market in proportion to the corresponding firms' strengths [72]. They cede dominance to their stronger competitors in those market segments where they are less efficient, while in exchange the latter do the same in segments where the former are more efficient [73]. Such developed codependence gradually motivates the firms to de-escalate rivalry [74]. Eventually, the rates of entry and exit in the market decrease [75], and interfirm hostility declines [76].

This assumed market landscape generally means that the technology involved and the relevant business operations have been standardized. So, if an entrepreneur eyes on such a market for the potential of profitable entry, it is reasonable to assume that the entrepreneur's firm has come up with a more efficient technology and/or operation that can greatly reduce the overall business expenditure. As a reference, for example, Moeen [77] examines the capability antecedents of firm entry into nascent industries, where a firm's technological investments in nascent industries typically occur before its market entry. Considering the fact that this new firm does not have any loyal consumer in the target market, it has to first aim at acquiring as many switchers as possible. To do so, assume that this firm uniformly randomizes its price $P$ over the interval $[0,1]$ as long as the firm could make profits on the average, where 0 is assumed to be the constant marginal costs of this new firm without loss of generality and 1 the reservation price the loyal consumers of the incumbent firms are willing to pay for their purchases from their respective firms.

Because the incumbent firms are in a state of forbearance, without loss of generality consider the aggregate of the incumbents as one firm, whose proportion of market occupancy is $\alpha$. So, $\beta=1-\alpha$ represents the proportional size of the market segment of switchers who base their purchase decisions on which price is lower. Then, the following result holds true:

Theorem 1. As of the afore-described oligopoly market, in the Nash equilibrium, if the consumer surplus $\beta$ is greater than 0 , then at least one new firm would profitably enter the market; and the scale of the entering firm in terms of its operation in this market will be proportional to the magnitude of $\beta$.

Proof. Let $\alpha_{0}$ be a real number so that $\beta=1-\alpha>\alpha_{0}>0$ and $\alpha=\ell \alpha_{0}$. Imagine that the aggregate firm is divided into $\ell$ many identical "firms", named $i, \quad i=1,2, \cdots, \ell$. Each of them provides consumers with identical products and enjoys the market share $\alpha_{0}=\alpha / \ell$ of loyal consumers. These imaginary 
firms compete over the switchers with adjustable prices. Because these imaginary firms are really equal partitions of the same aggregate firm, they have the same constant marginal cost, which is set to zero as what is assumed earlier, the managements of these firms are fully aware of the pricing strategies used by all the firms (because the firms are managed by the same administrative unit), and they establish their best, identical responses by playing the Nash equilibrium through their unified self-analyses.

Next, these $\ell$ imaginary firms do not have any symmetric pure strategy Nash equilibrium (For the setup here, there is no need to consider asymmetric pure strategy Nash equilibrium, because all these imaginary firms take identical actions). In fact, for any symmetric pure strategy portfolio $\left(x_{1}, x_{2}, \cdots, x_{\ell}\right)$, where $x_{i}=x_{j}$, for $i, j=1,2, \cdots, \ell$, a randomly chosen Firm $(j \in\{1,2, \cdots, \ell\})$ can slightly lower its price from $x_{j}$ to $x_{j}^{\prime}$ to produce additional profits for all the firms as long as $x_{j}^{\prime} \beta>\left(x_{j}-x_{j}^{\prime}\right) \alpha$, which is possible to do by adjusting $x_{j}^{\prime}$ sufficiently close to $x_{j}$. So, $\left(x_{1}, x_{2}, \cdots, x_{\ell}\right)$ is not Nash equilibrium. Even so, Forrest et al. [71] show that these $\ell$ firms do have symmetric mixed-strategy Nash equilibrium.

For the rest of this proof, it suffices to show that there is at least one firm that will be expected to profit by entering this market through uniformly randomizing its price strategy over the interval $[0,1]$.

Let $F_{j}(P)=F(P)$ be the price distribution of Firm $j$, one of the imaginary firms of the aggregate firm. The aggregate firm or equivalently each of the $\ell$ imaginary forms sets its price after taking into account the price of the entering firm and those of all other imaginary firms. Hence, the profits for Firm $j$ from its loyal consumers is $\alpha_{0} P$ and those from its share of the switchers is $(1-P) \beta P \prod_{i \neq j}^{\ell}\left[1-F_{j}(P)\right]=\beta P(1-P)[1-F(P)]^{\ell-1}$. Hence, the profits $\Pi$ Firm $j$ generates when the firm sells its product at price $P$ are

$$
\alpha_{0} P+\beta P(1-P)[1-F(P)]^{\ell-1}
$$

and the expected profits of Firm $j$ for all possible prices are given by

$$
\begin{aligned}
E(\Pi) & =\int_{-\infty}^{+\infty}\left\{\alpha_{0} P+\beta P(1-P)[1-F(P)]^{\ell-1}\right\} \mathrm{d} F(P) \\
& =\int_{0}^{1}\left\{\alpha_{0} P+\beta P(1-P)[1-F(P)]^{\ell-1}\right\} \mathrm{d} F(P),
\end{aligned}
$$

where the objective for Firm $j$ is to maximize its expected profits by choosing its price distribution $F(P)$. The reason why the upper and lower limits of the integral are changed respectively from $+\infty$ and $-\infty$ to 1 and 0 is because when $P<0$ or when $P>1$, the profits are zero.

The equilibrium indifference condition of Firm $j$ is

$$
\alpha_{0} \times P+\beta \times P(1-P)[1-F(P)]^{\ell-1}=\alpha_{0} \times 1
$$

So, for the $\ell$ imaginary firms, solving Equation (3) leads to their symmetric equilibrium pricing strategy as follows: 


$$
F(P)=1-\left(\frac{\alpha_{0}}{\beta P}\right)^{\frac{1}{\ell-1}} .
$$

From $\beta>\alpha_{0}$, it follows that $\alpha_{0} / \beta<1$. So, for any price $P$, satisfying $1 \geq P \geq \alpha_{0} / \beta$, Equation (4) is a well-defined probability distribution. This end implies that for the $\ell$ imaginary firms, or equivalently, the aggregate firm, the lowest allowed price is $\alpha_{0} / \beta$.

To complete this proof, it suffices to show that the entering firm actually expects to make profits in this new market. To this end because $\lim _{P \rightarrow 1}-F(P)=1-\left(\alpha_{0} / \beta\right)^{1 /(\ell-1)} \neq F(1)=1$, the cumulative price distribution function $F(P)$ has a jump discontinuity at the reservation value $P=1$, where the amount of jump is $\left(\alpha_{0} / \beta\right)^{1 /(\ell-1)}$. That is, $F(P)$ has a mass point of size $\left(\alpha_{0} / \beta\right)^{1 /(\ell-1)}$ at the reservation price $P=1$. So, the expected profits of the entering firm are the following:

$$
\begin{aligned}
E(\Pi) & =\int_{0}^{\alpha_{0} / \beta} \beta P \mathrm{~d} P+\int_{\alpha_{0} / \beta}^{+\infty} \beta P[1-F(P)]^{\ell} \mathrm{d} P \\
& =\int_{0}^{\alpha_{0} / \beta} \beta P \mathrm{~d} P+\int_{\alpha_{0} / \beta}^{1} \beta P[1-F(P)]^{\ell} \mathrm{d} P+\beta\left(\frac{\alpha_{0}}{\beta}\right)^{\ell /(\ell-1)}
\end{aligned}
$$

where the first term in the right-hand side of Equation (5) stands for the expected profits of the entering firm when it charges the lowest price in the marketplace and captures the entire segment of the switchers, and the second term is the entering firm's expected profits when it is in direct competition with the $\ell$ incumbent firms.

Because the first and third terms in the right-hand side of Equation (5) are positive while the second term is $\geq 0$, it follows that the expected profits $E(\Pi)$ of the entering firm is greater than zero. That is, if the consumer surplus $\beta=1-\alpha>0$, there will be at least one small startup that will enter the market to compete with the incumbent firms.

From Equations (5), it follows that

$$
E(\Pi) \geq \int_{0}^{\alpha_{0} / \beta} \beta P \mathrm{~d} P+\beta\left(\frac{\alpha_{0}}{\beta}\right)^{\ell /(\ell-1)}
$$

So, the expected profits $E(\Pi)$ of the entering firm is an increasing function of $\alpha_{0}$. Since $\alpha_{0}$ satisfies $\beta>\alpha_{0}>0$ and is arbitrary, we conclude that the scale of the entering firm will be proportional to the magnitude of $\beta$, where the magnitude of the expected profits is used as an indicator of the scale of the entering firm.

\subsection{How the Market Stimulates Innovation}

In the development of Theorem 1, the market is assumed to be occupied by $m$ incumbent firms, where $m$ can be any of the natural numbers $1,2,3, \ldots$ If $m=1$, the market is monopolized by one incumbent firm. In this case, the systemic yoyo structure of the market is shown in Figure 2 when seen from either the 


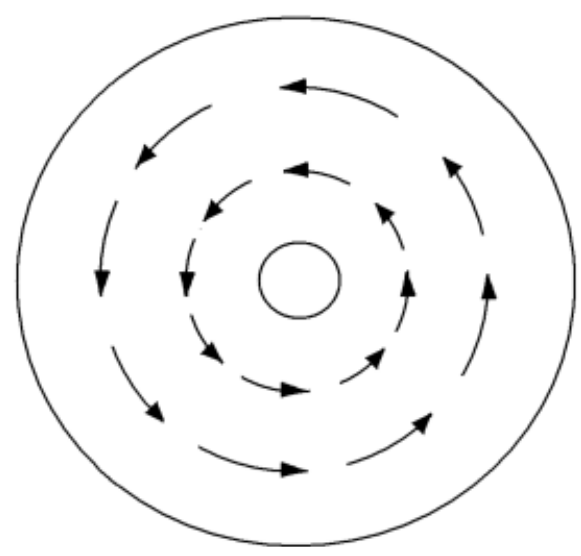

Figure 2. The market structure when $m=1$.

black-hole side or the big-pang side. Now, the condition in Theorem 1 that the consumer surplus $\beta$ is greater than 0 means that within the uniform flow of things in the systemic yoyo field of the market there appear some elements that do not like to flow with the mass. In other words, the prior uniform movement of the field starts to break down and some local chaos begins to emerge. In practice, such situations often appear with monopolized markets because the products, supplied by the monopolist overtime, can no longer satisfy the constantly evolving desires and tastes of the consumers.

When local chaos appears within the previously uniform flow of things of the market, Figure 2, Theorem 1 implies that there will be at least one new firm to profitably enter the market. So, the originally uniform pattern of the market in Figure 2 will eventually evolve into that in Figure 3, where the number of eddy leaves (regional spinning pools) depends on how intense the market competition is becoming. For more details regarding this end, see the dishpan experiment initially observed by Raymond Hide [78] of Cambridge University, England, and then by Dave Fultz and his colleagues of University of Chicago [79].

If the market is expanding, as that of the personal computers in the 1970s until recent times, then the boundaries of the dishes in Figure 3 swell outwards; if the market dwindles, then the boundaries implode and the scale of the dishes gets smaller.

When the market is in a state as described in Figure 3, we have $m \geq 2$. Theorem 1 now indicates that as long as there is a sufficiently large market segment of switchers, which means that within the spinning pool in Figure 3(a) and Figure 3(b) there appear some unoccupied areas, there will be firms to grab the undecided market segment. As a matter of fact, we have the following result regarding the long-term evolution of the market dynamics:

Theorem 2. For the afore-described market, if the market experiences an increasing number of profitable entrants, then consumer loyalty will diminish overtime.

Proof. Continuing the reasoning employed in the proof of Theorem 1, this market does not have any pure strategy Nash equilibrium and nonsymmetrical 


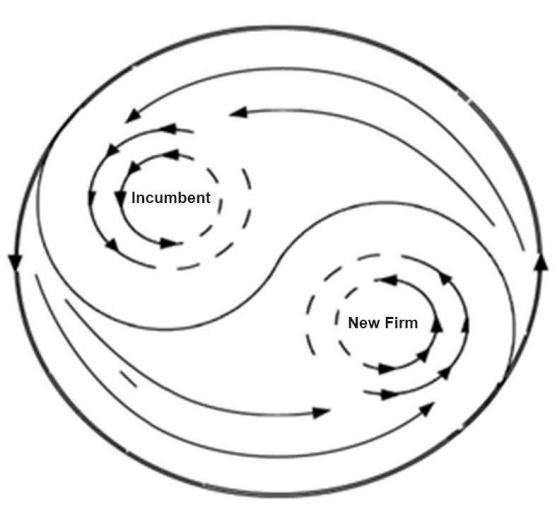

(a)

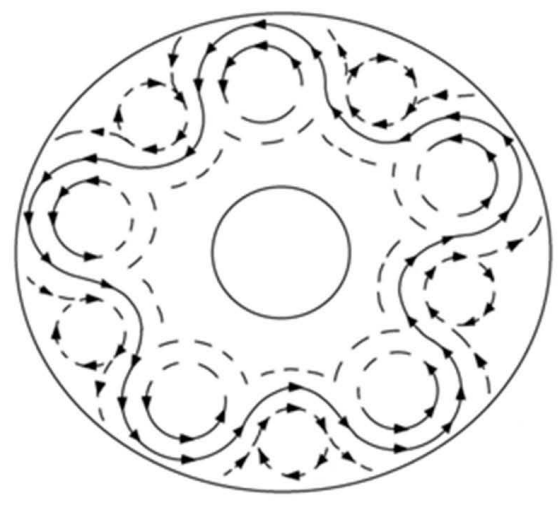

(b)

Figure 3. A new field pattern of the market. (a) Only one entrant; (b) Multiple entrants.

mixed strategy Nash equilibrium [71]. Let $F_{i}(P)$ be the price distribution of Firm $i \in\{1,2, \cdots, m\}$, which compete with each to attract switchers by adjusting their selling price $P$. The assumption of an increasing number of entrants implies that the consumer surplus satisfies $\beta=1-m \alpha>0$, where $m \alpha$ stands for the size of loyal consumers of the incumbent firms. Assume that there are $n$ new firms that enter the market by uniformly randomizing its price $P$ over the interval $[0,1]$, where their cost basis is also assumed to be constant and set to zero. Then, the profits of incumbent Firm $i$ are given by

$$
\alpha P+\beta P(1-P)^{n} \prod_{j \neq i}^{m}\left[1-F_{j}(P)\right]
$$

and the expected profits of Firm $i$ is

$$
E\left(\Pi_{i}\right)=\int_{0}^{1}\left\{\alpha P+\beta P(1-P)^{n} \prod_{j \neq i}^{m}\left[1-F_{j}(P)\right]\right\} \mathrm{d} F_{i}(P),
$$

where the objective of the firm is to maximize its expected profits through selecting the appropriate price distribution $F_{i}(P)$.

The equilibrium indifference condition for incumbent Firm $i$ is

$$
\alpha \times P+\beta \times P(1-P)^{n} \prod_{j \neq i}^{m}\left[1-F_{j}(P)\right]=\alpha \times 1 .
$$

So, the symmetric equilibrium price strategy of each incumbent Firm $i$, $i=1,2, \cdots, m$, is

$$
F(P)=F_{i}(P)=1-P^{\frac{-1}{m-1}}(1-P)^{-\frac{n-1}{m-1}}\left(\frac{\alpha}{\beta}\right)^{\frac{1}{m-1}}=P^{\frac{-1}{m-1}}(1-P)^{-\frac{n-1}{m-1}} h(P),
$$

where $h(P)=P^{\frac{1}{m-1}}(1-P)^{\frac{n-1}{m-1}}-\left(\frac{\alpha}{\beta}\right)^{\frac{1}{m-1}}$.

For this strategy $F(P)$ to be valid, we must have $F(P)=0$, for $P \leq \underline{P}$, $F(P)=1$, for $P \geq \bar{P}$, and $F(P) \geq 0$, for $\underline{P} \leq P \leq \bar{P}$, where $\underline{P}$ and $\bar{P}$ are some fixed price levels such that $0 \leq \underline{P}<\bar{P} \leq 1$.

For such price levels $\underline{P}$ and $\bar{P}$ to exist, $h(P)$ must satisfy $h(P) \geq 0$, for 
$\underline{P} \leq P \leq \bar{P}$, where $\underline{P}$ and $\bar{P}$ are some fixed price levels such that $0 \leq \underline{P}<\bar{P} \leq 1$, and that $h(0)<0$ and $h(1)<0$. Since

$$
h^{\prime}(P)=\frac{1}{m-1} P^{\frac{1}{m-1}}(1-P)^{\frac{n-1}{m-1}}\left[P^{-1}-(n-1)(1-P)^{-1}\right],
$$

it can be shown that $h(P)$ reaches its maximum at $P=1 / n$. That is, in order for the previously mentioned price levels $\underline{P}$ and $\bar{P}$ to exist, $h(P)$ must satisfy $h\left(\frac{1}{n}\right)>0$, which means

$$
\frac{\alpha}{\beta}<\frac{1}{n}\left(1-\frac{1}{n}\right)^{n-1}=\left(1-\frac{1}{n}\right)^{n}\left(1-\frac{1}{n}\right) \frac{1}{n} .
$$

So, when $n \rightarrow \infty, \alpha / \beta(1 / e) \times 1 \times 0=0$. This end means that the market segment of loyal consumers of the incumbent firms gradually diminishes with an increasing number of new firms entering the market.

By combining Theorem 2 with Theorem 1, we can see the following market force that stimulates innovation in manufacturing firms: If a market is either emerging or expanding, that is, the boundaries of the dishes in Figure 2 and Figure 3 are pushing outwards, then all firms, be they startups or incumbents, have to constantly strive for newer and better products because they cannot depend on the so-called loyal consumers to maintain their business. On the other hand, if the market is quite stable, then earlier analysis implies that the systemic yoyo field structure of the market will be depicted like that in Figure 3(b). Now, if the incumbent firms do not continuously introduce newer and better versions of their products (sold at prices within comsumers' budget constraints), then the consumers' evolving desire and taste will lead to a growing market segment of switchers, which in turn will invite new competition from outside the stable market. In other words, as long as the market is not located within a planned economy, then the evolution of market activities will naturally stimulate innovation in manufacturing firms.

\section{Dominant Environmental Determinants of Innovation}

Among the nearly 40 internal and 20 environmental determinants of innovation studied in the literature since the late 1960s [7], we use the logic of systemic thinking and Theorems 1 and 2 established in the previous section to pinpoint out the dominant determinants regarding in the general analysis of innovation. To that end, we assume that each and every firm in the business world exists for the purpose of satisfying a particular market niche through generating a positive cash flow. The positive cash flow can be a result of profits from the marketplace, or investments from various investors, or both.

Investments generally follow the promising future of the business of concern even though the business might not be currently making any profits, such as Tesla, SpaceX, etc., in 2017. Because the purpose of this study is on the topic of innovation in manufacturing sector, without loss of generality this section will 
only focus on the established manufacturing firmswhere both incremental and radical innovative changes take place. In other words, this section will not consider business entities established for the only purpose of playing around potentials of a novelty without any market share in an existing market in order to try their luck with the so-called first-mover advantage [80]. So, our starting point for this section is the assumption that each and every firm in manufacturing sector has to make profits to survive, which in terms of the systemic yoyo model means that the yoyo structure of each firm has to maintain its equilibrium with the market environment; otherwise the firm will cease to exist.

Based on how the market invites competition and stimulates innovation as established in the previous discussions and as recognized by the contingency theory in the literature [67] [68] [69] [70], we examine the dominating environmental determinants of innovation. These environmental determinants are grouped into six categories by Becheikh et al. [7] as follows:

1) The industry to which the firm belongs;

2) The region where the firm is located;

3) What culture is surrounding the firm;

4) Its networking relations with various actors of the firm's environment;

5) How the firm acquires knowledge and technologies; and

6) What government and public sector policies the firm is under.

\subsection{Industry}

The "industry" category consists of such determinants as "technological dynamism", "demand growth", and "industry structure". In terms of technological dynamism, the systemic reason why high-tech industries, such as telecommunication, aerospace, pharmaceutical, are more innovative than traditional ones, such as textile, wood, food, as shown by Kam et al. [81], Quadros et al. [82] and Uzun [83], is because the markets of the former are more dynamic than those of the latter, indicating that the markets of high-tech industries are more stimulating and inviting with their boundaries constantly pushed outwards into new territories. In terms of demand growth, the systemic reason why its effect on innovation is significant, as shown by Baptista and Swann [84], Michie and Sheehan [85] and Zahra [86], is that there are always new consumers in the market looking for newer and better quality products, which according to Theorem 1, leads to increasing market competition that in turn stimulates companies to innovate in order to stay ahead of their business game. In terms of industry structure, such as those with low technological entry barriers and a high competition level and those where economies of scale raise entry barriers, the empirical evidence on its effect on innovation is very mixed, ranging quite evenly among positive effects, insignificant effects, and negative associations [87] [88] [89] [90].

Although the effect of the determinants in this category on innovation is widely accepted in the literature [81] [86] [88] [91], the relevant empirical studies actually produce mixed results, reflecting the uncertain nature of the me- 
thods of data mining. On the other hand, by using the logic of systemic thinking, we can also identify "demand growth" as the dominating determinant of innovation, where "technological dynamism" is closely related to "demand growth" through various means, such as the opening up of new markets-a sign of demand growth, introduction of improved products with much improved functionalities-an attraction for a wider population of consumers, etc.

\subsection{Region}

The "region" category consists of such determinants as geographic "location" of the firm [92] and "proximity" advantage [93]. The systemic reason for why determinant "location" has significant effects on the firm"s innovative capacity [94] is that good "locations" generally represent clusters of high demands; with sufficient demands emerging in one place there will be a sizable market forming in the location. So, Theorem 1 implies that as soon as a market is in place to help connect sellers and buyers, the market competition will naturally intensify with demands. The increasing pressure of competition naturally forces the construction of new infrastructure and improvement of the existing infrastructure, while attracting specialized workforces from surrounding areas, as supported by empirical studies of Blind and Grupp [95] and Sternberg and Arndt [92]. Similarly, determinant "proximity" measures how conveniently the firm can draw into its yoyo field the inputs it needs to thrive, such as suppliers, consumers, information, knowledge, R\&D capability, financial institutions, etc. All such conveniences help facilitate tacit knowledge transfer, reduce communication costs, support interpersonal interactions, and develop trust and a social capital between partners, all of which reduce the risk and uncertainty related to innovation. Therefore, "proximity" bears significant effects on the innovativeness of the firm, as empirically shown by Romijn and Albaladejo [93], Uzun [83], and others.

Considering how internet-based markets have become maturely developed in recent years, between the two determinants "location" and "proximity" we would choose the latter as a dominating determinant. It is because market demand is no longer limited by where the firm is physically located, while the specialized workforce that is directly involved in innovations can be mobilized over long distances.

\subsection{Culture}

The category of the "surrounding culture" of the firm consists of such factors as external financial support [96] [97], power distance, risk avoidance, femininity-masculinity, collectivism-individualism, and temporal orientation [65] [98] [99] [100]. Similar to the case of the previous category of "policies", although the firm, seen as a spinning yoyo, has its own particular organizational culture, it has to operate within a larger culture, seen as a spinning pool of many smaller yoyos. However, the surrounding, large-scale culture generally determines the govern- 
ment and public sector policies [101]. So, there is no need to single out this category in the study of environmental determinants on innovation (see [53]) for a discussion on the culture within the firm), although the specified factors in the literature should and could be considered as some of the internal determinants. This systemic conclusion actually explains why the related empirical studies on this category of the "surrounding culture" are extremely rare, producing varied and often not significant results.

\subsection{Networking}

The "networking" category represents interactions with various stakeholders, such as universities, research centers, industrial and professional associations, consultants, service providers, suppliers, and consumers [93] [97] [102] [103] [104]. From the assumption that each and every firm is assumed to exist for the purpose of satisfying a particular market niche through generating a positive cash flow, the systemic yoyo model surely indicates that this "networking" category bears extremely important impact on innovations of the firm through inputting whatever necessary for the firm to make adjustments and to reposition itself in the marketplace. These interactions help provide the firm with new and crucial information and knowledge and additional resources, all of which strengthen the competitiveness of the firm or the intensity of spin of the yoyo structure of the firm. To a truly theoretical height this systemic conclusion carries the relevant empirical discoveries [10] [93] [94] [96] [104] [105] [106], which are either positive or non-significant. And in this context, the pattern of movement in Figure 1(c) indicates that in general the innovation process represents anonlinear evolution of ideas and related processes on how to implement the ideas into marketable products, as empirically confirmed by various authors such as Dosi et al. [107], Kaufmann and Todtling [94], Kline and Rosenberg [108], and Malecki [109].

The category of "how knowledge/technology is acquired" by the firm consists of both formal and informal acquisitions and takes various forms, such as the purchase of equipment, licenses, and sponsorship agreements, the attendance of conferences and specialized fairs, or simply the informal exchanges with various actors in a firm's environment [104] [110] [111]. Although the systemic yoyo model indicates that although the firm could be exposed to different sources of information and technology and bombarded with all the relevant know-hows, it does not naturally mean that the firm would consequently absorb what is useful and beneficial in term of innovative activities. This end is determined by the existing knowledge structure, strategic orientation, organizational culture, and the general characteristics of the firm. For example, in 1979 although Tom Whiteley, the head of Kodak's Emulsion Research Division, observed presentations of overhead projector slides generated on Xerox Alto, an early version of a personal computer, he and his fellow researchers of Kodak somehow did not see the future of the new technology. Instead, they were very much engulfed in how well-entrenched the Kodak technology was. So, Kodak continued to exploit and 
strengthen its long-standing advantages in film, while Fuji Photo moved into a future without film [1]. Hence, systemically speaking, this category of environmental determinants can be and should be entirely merged with the firm's internal determinants of innovation. Empirically, what is concluded here through employing systemic thinking is well explained by the inconclusive results of data mining [83] [94] [103] [110] [111] [112].

\subsection{Knowledge and Technologies}

Knowledge and technologies are fundamentally important because, in practice, how much a piece of known information and knowledge can be beneficially understood and converted into marketable products is really determined by the firm's absorptive capacity and its unwavering desire to lead the market trends [104]. Firms that are determined, which in practice leads to the relevant capability [1], to assimilate, adapt and transform newly acquired knowledge and technology have better chance of employing them to innovate than those firms that are not so determined. In other words, most pieces of information and knowledge can be comprehended in many different ways, some of which lead to marketable products while others might only provide a degree of learning pleasure without producing any tangle outcomes.

That is, the category of "how knowledge/technology is acquired" by the firm needs to be merged with the firm's internal determinants of innovation instead of being considered as an environmental determinant.

\subsection{Government and Public Sector Policies}

The category of the "government and public sector policies", under which the firm operates, affects the innovativeness of the firm [113] [114], because the systemic yoyo structure of the firm is surely part of a much larger and more powerful yoyo field of the government and the public sector, although locally the firm could alter its field pattern slightly. For example, the government policy could favor the development of certain sectors, substitute for imports, promote environmental management, etc., all of which in turn have a significant positive effect on innovation of the relevant firms [113] [114] [115]. Similarly, financial supports granted by governments, professional organizations, and financial institutions encourage firms to innovate more [93] [96] [97] [112].

Summarizing what is discussed in this section the following are the dominating environmental determinants on innovation of manufacturing firms: "demand growth", "proximity", "networking”, and "government and public sector policies".

\section{Recommendations Developed on the Newly Established Theory}

Although each company has its individual characteristics and specificities, the results of this paper highlight several avenues which will help managers and pol- 
icy makers to better foster innovation and researchers to better channel their efforts in studying the phenomenon of innovation.

Specifically, for managers, encouraging innovation starts with a clear reception and an inventive understanding of the market signals, be they market invitations or stimulations, and the government and public sector policies. And then they align their firm's strategies with the received signal and the particular comprehension of the policies through building up the firm's distinctive competencies and by the willingness to go beyond the existing market territory through entering new markets-generating demand growth. The structure of the firm needs to be flexible so that units of the R\&D department can be near different centers of information and knowledge, units of the sales department conveniently located near consumers, units of production easily reached by suppliers, etc. That is, the determinant "proximity" of innovation needs to be effectively considered and implemented in various ways. When designing the geographic distribution of various business units, managers must also take into consideration the networking capability of the distribution with stakeholders, such as financial institutions, suppliers, universities, research centers, etc. They must take advantage of such network system to create various cooperative relationships with all potentially valuable partners.

For policy makers, the most important decision in fostering innovation in the manufacturing sector is to encourage competition in the marketplace by eliminating as much entry barriers as possible, by preventing the employment of strategies developed by firms that lead to monopolistic situations in the marketplace, and by setting up institutions that help companies conduct their business beyond their traditional territories and internationally. When policies are introduced to promote innovation, they need to be communicated clearly about where things are expected to happen, what needs to be achieved, and what kinds of financial supports will be available. In particular, policy makers can foster innovation by introducing various initiatives and by establishing geographical clusters of industries and technology centers through constructing specialized infrastructure and research facilities.

Based on our previous discussions, these recommendations in general (but not in particular) are expected to work reliably in practice because they are based on rigorous reasoning instead of conjectures developed on data mining and anecdotes. That really sets this work apart from the empirical literature, on which derived recommendations can only be suggestions because all the relevant studies suffer from major weaknesses that prevent the decision/policy maker from making generalizations. In particular, the major weaknesses in empirical studies stem from how various variables are measured and how the collected data are analyzed, which lead to an additional problem when comparing data across countries, since the documentation of such data vary widely across nations. The first weakness involves measurement uncertainty [116] while the second weakness the limitations of the tools of data mining [117]. For example, the very concept of innovation has been measured with various indicators, while 
none of the indicators really measure the same underlying construct. At the same time, explanatory variables (or determinants) of innovation have been differently operationalized by various authors [7]. The different indicators and operationalizations are not necessarily correlated, creating similarly worded results that do not necessarily possess comparable meanings. Such a research challenge cannot be easily met due to the fact that the methodologies often employed cannot and should not be standardized-because each methodology has its strengths and weaknesses, while similar problems exist with the definition and measurement of variables. Although difficult, future research needs to address this challenging problem in one way or another; and we submit that a systems science approach is a beneficial methodology that will, when practically employed, produce insightful understandings on manufacturing innovation.

\section{Conclusions}

This work complements recent systemic studies on how a firm needs to prepare itself internally for the new era of fast evolving markets and transient competitive advantages [53] [118] and brings all the empirical investigations on the environmental determinants of innovation in manufacturing sector to the height of sound scientific abstraction. The significance of this paper is that through the holistic view of systems science and the rigor of game theory we are able to establish results and conclusions with practical certainty and reliability. That is; a holistic view and game theory can be useful when utilized toward understanding innovation, representing a substantially different approach from those already established in the literature.

The literature of relevant empirical studies collectively shows the complexity of innovation in manufacturing sector. Nearly twenty environmental variables that more or less explain innovation in manufacturing firms are identified by various scholars over a time span of several decades. However, the empirical results on how effective these identified variables are on innovation have been mostly mixed with some positive while others negative [7]. So, when managers need to make their practical decisions based on such mixed results, a lot of uncertainties appear with what kinds of outcomes would be produced out of their decided actions. Compared to the theoretical and practical uncertainties extant in the literature, this work walks in the opposite direction by greatly simplifying the complexity of innovation through uncovering the market invitation and stimulation for individual firms to engage in innovative activities and then by identifying four dominating environmental determinants on innovation. Additionally, this work shows definitively when the market invites competition and innovation and how a manufacturing firm will be losing its loyal consumers if it does not answer proactively the calls of the market.

As for the limitation of this study, all conclusions are derived based on our definition of innovation in the manufacturing sector and a key assumption about why each and every firm in the business world exists. The former is specified as an activity or a set of activities that leads to exceptionally added value to the 
company when compared to other activities that take place in the same sector. And the latter maintains that each and every firm in the business world exists for the purpose of satisfying a particular market niche through generating a positive cash flow, which can be a result of profits from the marketplace, or investments from various investors, or both. In particular, our employed concept of innovation does not include small-scale, incremental improvements that might amount to major innovative business successes in the long term. However, many important disruptive breakthroughs, which have provided exceptionally added value in the past, appear as accumulated efforts and small-scale incremental progresses over time [55] [119]. So, our assumption on why firms in the business world exist does not include situations where firms are established for purposes other than satisfying a market niche. These limitations of the current paper point to some important questions that need to be addressed in future research works.

\section{Conflicts of Interest}

The authors declare no conflicts of interest regarding the publication of this paper.

\section{References}

[1] McGrath, R.G. (2013) The End of Competitive Advantage: How to Keep Your Strategy Moving as Fast as Your Business. Harvard Business Review Press, Boston.

[2] Schumpeter, J.A. (1934) The Theory of Economic Development. Harvard University Press, Cambridge.

[3] Brown, S.L. and Eisenhardt, K.M. (1995) Product Development: Past Research, Present Findings, and Future Directions. Academy of Management Review, 20, 343-378. https://doi.org/10.5465/amr.1995.9507312922

[4] OECD (1997) The Measurement of Scientific and Technological Activities, Proposed Guidelines for Collecting and Interpreting Technological Innovation Data. Organization for Economic Cooperation and Development, Paris.

[5] Rosenthal, S.R. (1992) Effective Product Design and Development. Irwin, Homewood.

[6] Stock, G.N., Greis, N.P. and Fischer, W.A. (2002) Firm Size and Dynamic Technological Innovation. Technovation, 22, 537-549. https://doi.org/10.1016/S0166-4972(01)00061-X

[7] Becheikh, N., Landry, R. and Amara, N. (2006) Lessons from Innovation Empirical Studies in the Manufacturing Sector: A Systematic Review of the Literature from 1993 to 2003. Technovation, 26, 644-664. https://doi.org/10.1016/j.technovation.2005.06.016

[8] Marzi, G., Dabic, M., Daim, T. and Garces, E. (2017) Product and Process Innovation in Manufacturing Firms: A 30-Year Bibliometric Analysis, Scientometrics, 113, 673-704. https://doi.org/10.1007/s11192-017-2500-1

[9] Souitaris, V. (1999) Research on the Determinants of Technological Innovation. A Contingency Approach. International Journal of Innovation Management, 3, 287-305. https://doi.org/10.1142/S1363919699000153

[10] Souitaris, V. (2002) Technological Trajectories as Moderators of Firm-Level Determinants of Innovation. Research Policy, 31, 877-898. 
https://doi.org/10.1016/S0048-7333(01)00154-8

[11] Wolf, R.A. (1994) Organisational Innovation: Review, Critique and Suggested Research Directions. Journal of Management Studies, 31, 405-431. https://doi.org/10.1111/j.1467-6486.1994.tb00624.x

[12] Coombs, R., Narandren, P. and Richards, A. (1996) A Literature-Based Innovation Output Indicator. Research Policy, 25, 403-413. https://doi.org/10.1016/0048-7333(95)00842-X

[13] Lin, Y. and OuYang, S.C. (2010) Irregularities and Prediction of Major Disasters. CRC Press, an imprint of Taylor and Francis, New York. https://doi.org/10.1201/9781420087468

[14] Smith, A. (1776) The Wealth of Nations, Books I-III. Penguin Books, London.

[15] Aas, T.H., Breunig, K.J., Hydle, K.M. and Pedersen, P.E. (2015) Innovation Management Practices in Production-Intensive Service Firms. International Journal of Innovation Management, 19, 1-28. https://doi.org/10.1142/S1363919615500553

[16] Adner, R. and Levinthal, D. (2001) Demand Heterogeneity and Technology Evolution: Implications for Product and Process Innovation. Management Science, 47, 611-628. https://doi.org/10.1287/mnsc.47.5.611.10482

[17] Damanpour, F. (1991) Organizational Innovation: A Meta-Analysis of Effects of Determinants and Moderators. The Academy of Management Journal, 34, 555-590. https://doi.org/10.5465/256406

[18] Visnjic, I., Wiengarten, F. and Neely, A. (2016) Only the Brave: Product Innovation, Service Business Model Innovation, and Their Impact on Performance. Journal of Product Innovation Management, 33, 36-52. https://doi.org/10.1111/jpim.12254

[19] Smith, W.K. and Tushman, M.L. (2005) Managing Strategic Contradictions: A Top Management Model for Man-Aging Innovation Streams. Organization Science, 16, 522-536. https://doi.org/10.1287/orsc.1050.0134

[20] Kanter, R.M. (2001) Evolve! Succeeding in the Digital Culture of Tomorrow. Harvard Business School Press, Boston.

[21] Daft, R.L. (1978) A Dual-Core Model of Organizational Innovation. Academy of Management Journal, 21, 193-210. https://doi.org/10.2307/255754

[22] Damanpour, F. (1987) The Adoption of Technological, Administrative, and Ancillary Innovations: Impact of Organizational Factors. Journal of Management, 13, 675-688. https://doi.org/10.1177/014920638701300408

[23] Utterback, J.M. and Abernathy, W.J. (1975) A Dynamic Model of Process and Product Innovation. Omega, 3, 639-656. https://doi.org/10.1016/0305-0483(75)90068-7

[24] Ettlie, J.E., Bridges, W.P. and O'Keefe, R.D. (1984) Organization Strategy and Structural Differences for Radical versus Incremental Innovation. Management Science, 30, 682-695. https://doi.org/10.1287/mnsc.30.6.682

[25] Nord, W.R. and Tucker, S. (1987) Implementing Routine and Radical Innovation. Lexington Books, Lexington.

[26] Veugelers, R. and Cassiman, B. (1999) Make and Buy in Innovation Strategies: Evidence from Belgian Manufacturing Firms. Research Policy, 28, 63-80. https://doi.org/10.1016/S0048-7333(98)00106-1

[27] Amara, N. and Landry, R. (2005) Sources of Information as Determinants of Novelty of Innovation in Manufacturing Firms: Evidence from the 1999 Statistics Canada Innovation Survey. Technovation, 25, 245-259. 
https://doi.org/10.1016/S0166-4972(03)00113-5

[28] Nieto, M.J. and Santamaria, L. (2007) The Importance of Diverse Collaborative Networks for the Novelty of Product Innovation. Technovation, 27, 367-377. https://doi.org/10.1016/j.technovation.2006.10.001

[29] De Massis, A., Frattini, F., Pizzurno, E. and Cassia, L. (2015) Product Innovation in Family versus Nonfamily Firms: An Exploratory Analysis. Journal of Small Business Management, 53, 1-36. https://doi.org/10.1111/jsbm.12068

[30] Alegre, J. and Chiva, R. (2008) Assessing the Impact of Organizational Learning Capability on Product Innovation Performance: An Empirical Test. Technovation, 28, 315-326. https://doi.org/10.1016/j.technovation.2007.09.003

[31] Lin, R.J., Tan, K.H. and Geng, Y. (2013) Market Demand, Green Product Innovation, and Firm Performance: Evidence from Vietnam Motorcycle Industry. Journal of Cleaner Production, 40, 101-107. https://doi.org/10.1016/j.jclepro.2012.01.001

[32] Caputo, A., Marzi, G. and Pellegrini, M.M. (2016) The Internet of Things in Manufacturing Innovation Processes: Development and Application of a Conceptual Framework. Business Process Management Journal, 22, 383-402. https://doi.org/10.1108/BPMJ-05-2015-0072

[33] Buffington, J. (2016) The Future of Manufacturing: An End to Mass Production. In: Frictionless Markets, Springer, Berlin, 49-65. https://doi.org/10.1007/978-3-319-19536-0_5

[34] Zollo, L., Marzi, G., Boccardi, A. and Ciappei, C. (2016) Glieffettidella Stampa 3D Sullacompetitivita Aziendale. Il casodelleimpreseorafe del distretto di Arezzo. Piccola Impresa/Small Business, 2, 80-100.

[35] Holmstrom, J., Holweg, M., Khajavi, S.H. and Partanen, J. (2016) The Direct Digital Manufacturing (r) Evolution: Definition of a Research Agenda. Operations Management Research, 9, 1-10. https://doi.org/10.1007/s12063-016-0106-Z

[36] Roos, G. (2015) Servitization as Innovation in Manufacturing: A Review of the Literature, In: The Handbook of Service Innovation, Springer, London, 403-435.

https://link.springer.com/chapter/10.1007/978-1-4471-6590-3_19 https://doi.org/10.1007/978-1-4471-6590-3_19

[37] Wu, D., Rosen, D.W., Wang, L. and Schaefer, D. (2015) Cloud-Based Design and Manufacturing: A Newparadigm in Digital Manufacturing and Design Innovation. Computer-Aided Design, 59, 1-14. https://doi.org/10.1016/j.cad.2014.07.006

[38] Lee, J., Bagheri, B. and Kao, H.A. (2015) A Cyber-Physical Systems Architecture for Industry 4.0-Based Manufacturing Systems. Manufacturing Letters, 3, 18-23. https://doi.org/10.1016/j.mfglet.2014.12.001

[39] Li, L. (2017) China's Manufacturing Locus in 2025: With a Comparison of "Made-in-China 2025" and "Industry 4.0". Technological Forecasting and Social Change, 135, 66-74. https://doi.org/10.1016/j.techfore.2017.05.028

[40] Asheim, B.T. and Isaksen, A. (1997) Location, Agglomeration and Innovation: Towards Regional Innovation Systems in Norway? European Planning Studies, 5, 299-330. https://doi.org/10.1080/09654319708720402

[41] Michie, J. (1998) Introduction. The Internationalisation of the Innovation Process. International Journal of the Economics of Business, 5, 261-277. https://doi.org/10.1080/13571519884387

[42] Schumpeter, J.A. (1950) The Process of Creative Destruction. In: Capitalism, Socialism and Democracy, 3rd Edition, Allen and Unwin, London.

[43] Coe, D.T. and Helpman, E. (1995) International R\&D Spillovers. European Eco- 
nomic Review, 39, 859-887. https://doi.org/10.1016/0014-2921(94)00100-E

[44] Engelbrecht, H.J. (1997) International R\&D Spillovers, Human Capital and Productivity in OECD Economies: An Empirical Investigation. European Economic Review, 41, 1479-1488. https://doi.org/10.1016/S0014-2921(96)00046-3

[45] Guellec, D. and de la Potterie, B.V.P. (2001) The Internationalisation of Technology Analysed with Patent Data. Research Policy, 30, 1253-1266. https://doi.org/10.1016/S0048-7333(00)00149-9

[46] Ireland, R.D. and Webb, J.W. (2007) Strategic Entrepreneurship: Creating Competitive Advantage through Streams of Innovation. Business Horizons, 50, 49-59. https://doi.org/10.1016/j.bushor.2006.06.002

[47] Pittaway, L., Robertson, M., Munir, K., Denyer, D. and Neely, A. (2004) Networking and Innovation: A Systematic Review of the Evidence. International Journal of Management Reviews, 5, 137-168. https://doi.org/10.1111/j.1460-8545.2004.00101.x

[48] Lansisalmi, H., Kivimaki, M., Aalto, P. and Ruoranen, R. (2006) Innovation in Healthcare: A Systematic Review of Recent Research. Nursing Science Quarterly, 19, 66-72. https://doi.org/10.1177/0894318405284129

[49] Camison-Zornoza, C., Lapiedra-Alcami, R., Segarra-Cipres, M. and Boronat-Navarro, M. (2004) A Metaanalysis of Innovation and Organizational Size. Organization Studies, 25, 331-361. https://doi.org/10.1177/0170840604040039

[50] Hobday, M. (2005) Firm-Level Innovation Models: Perspectives on Research in Developed and Developing Countries. Technology Analysis and Strategic Management, 17, 121-146. https://doi.org/10.1080/09537320500088666

[51] Peres, R., Muller, E. and Mahajan, V. (2010) Innovation Diffusion and New Product Growth Models: A Critical Review and Research Directions. International Journal of Research in Marketing, 27, 91-106. https://doi.org/10.1016/j.ijresmar.2009.12.012

[52] Crossman, M.M. and Apaydin, M. (2010) A Multi-Dimensional Framework of Organizational Innovation: A Systematic Review of the Literature. Journal of Management Studies, 47, 1154-1191. https://doi.org/10.1111/j.1467-6486.2009.00880.x

[53] Forrest, Y.L.J. and Nightingale, J. (2017) Successfully Transition into the Era of Transient Competitive Advantages. Proceedings of 2017 NABET Annual Conference, State College, 26-27 October 2017, 57-79.

[54] Christensen, C.M., Anthony, S.D. and Roth, E.A. (2004) Seeing What's Next: Using the Theories of Innovation to Predict Industry Change. Harvard Business School Press, Cambridge.

[55] Rostow, W.W. (1960) The Stages of Economic Growth: A Non-Communist Manifesto. Cambridge University Press, Cambridge.

[56] von Bertalanffy, L. (1924) Einfuhrung in Spengler's werk. LiteraturblattKolnischeZeitung.

[57] Porter, M.E. (1985) Competitive Advantage: Creating and Sustaining Superior Performance. Free Press, New York.

[58] Klir, G. (1985) Architecture of Systems Problem Solving. Plenum Press, New York. https://doi.org/10.1007/978-1-4757-1168-4

[59] Lin, Y. (2009) Systemic Yoyos: Some Impacts of the Second Dimension. Auerbach Publication, an Imprint of Taylor and Francis, New York. https://doi.org/10.1201/9781420088212

[60] Lin, Y. (1988) Can the World Be Studied in the Viewpoint of Systems? Mathematical and Computer Modelling, 11, 738-742.

https://doi.org/10.1016/0895-7177(88)90591-2 
[61] Lin, Y. (1999) General Systems Theory: A Mathematical Approach. Plenum and Kluwer Academic Publishers, New York.

[62] Klir, G. (2001) Facets of Systems Science. Springer, New York. https://doi.org/10.1007/978-1-4615-1331-5

[63] Kline, M. (1972) Mathematical Thought from Ancient to Modern Times. Oxford University Press, Oxford.

[64] Lin, Y. (2007) Systemic Yoyo Model and Applications in Newton's, Kepler's Laws, etc. Kybernetes. The International Journal of Cybernetics, Systems and Management Science, 36, 484-516. https://doi.org/10.1108/03684920710747101

[65] Wu, Y. and Lin, Y. (2002) Beyond Nonstructural Quantitative Analysis: Blown-ups, Spinning Currents and Modern Science. World Scientific, River Edge. https://doi.org/10.1142/4877

[66] Lin, Y., Ma, Y. and Port, R. (1990) Several Epistemological Problems Related to the Concept of Systems. Mathematical and Computer Modelling, 14, 52-57. https://doi.org/10.1016/0895-7177(90)90146-E

[67] Burns, T. and Stalker, G.M. (1961) The Management of Innovation. Tavistock, London.

[68] Chandler, A.D. (1962) Strategy and Structure: Chapters in the History of the American Industrial Enterprise. MIT Press, Cambridge.

[69] Lawrence, P.R. and Lorsch, J.W. (1967) Organization and Environment: Managing Differentiation and Integration. Division of Research, Graduate School of Business Administration, Harvard University, Boston.

[70] Woodward, J. (1970) Industrial Organization: Behavior and Control. Oxford University Press, London.

[71] Forrest, Y.L.J., Buttermore, J. and Wajda, T.A. (2017) At Nash Equilibrium When New Market Competitions Appear? Kybernetes. The International of Cybernetics, Systems and Management Science, 46, 256-271. https://doi.org/10.1108/K-11-2016-0311

[72] Bernheim, B.D. and Whinston, M.D. (1990) Multimarket Contact and Collusive Behavior. RAND Journal of Economics, 21, 1-26. https://doi.org/10.2307/2555490

[73] Li, S.X. and Greenwood, R. (2004) The Effect of Within Industry Diversification on Firm Performance: Synergy Creation, Multi-Market Contact and Market Structuration. Strategic Management Journal, 25, 1131-1153. https://doi.org/10.1002/smj.418

[74] Yu, T. and Cannella, A.A. (2012) A Comprehensive Review of Multimarket Competition Research. Journal of Management, 39, 76-109. https://doi.org/10.1177/0149206312462456

[75] Fuentelsaz, L. and Gómez, J. (2006) Multipoint Competition, Strategic Similarity and Entry into Geographic Markets. Strategic Management Journal, 27, 477-499. https://doi.org/10.1002/smj.529

[76] Haveman, H.A. and Nonnemaker, L. (2000) Competition in Multiple Geographic Markets: The Impact on Growth and Market Entry. Administrative Science Quarterly, 45, 232-267. https://doi.org/10.2307/2667071

[77] Moeen, M., (2017) Entry into Nascent Industries: Disentangling a Firm's Capability Portfolio at the Time of Investment versus Market Entry. Strategic Management Journal, 38, 1986-2004. https://doi.org/10.1002/smj.2642

[78] Hide, R. (1953) Some Experiments on Thermal Convection in a Rotating Liquid. Quarterly Journal of the Royal Meteorological Society, 79, 161.

https://doi.org/10.1002/qj.49707933916 
[79] Fultz, D., Long, R.R., Owens, G.V., Bohan, W., Kaylor, R. and Weil, J. (1959) Studies of Thermal Convection in a Rotating Cylinder with Some Implications for Large-Scale Atmospheric Motion. Meteorological Monographs, Vol. 4, American Meteorological Society, Boston. https://doi.org/10.1007/978-1-940033-37-2

[80] Lieberman, M.B. and Montgomery, D.B. (1988) First-Mover Advantages. Strategic Management Journal, 9, 41-58. https://doi.org/10.1002/smj.4250090706

[81] Kam, W.P., Kiese, M., Singh, A. and Wong, F. (2003) The Pattern of Innovation in Singapore's Manufacturing Sector. Singapore Management Review, 25, 1-34.

[82] Quadros, R., Furtado, A., Bernardes, R. and Franco, E. (2001) Technological Innovation in Brazilian Industry: An Assessment Based on the Sao Paulo Innovation Survey. Technological Forecasting and Social Change, 67, 203-219. https://doi.org/10.1016/S0040-1625(00)00123-2

[83] Uzun, A. (2001) Technological Innovation Activities in Turkey: The Case of Manufacturing Industry, 1995-1997. Technovation, 21, 189-196. https://doi.org/10.1016/S0166-4972(00)00033-X

[84] Baptista, R. and Swann, P. (1998) Do Firms in Clusters Innovate More? Research Policy, 27, 525-540. https://doi.org/10.1016/S0048-7333(98)00065-1

[85] Michie, J. and Sheehan, M. (2003) Labour Market Deregulation, "Flexibility" and Innovation. Cambridge Journal of Economics, 27, 123-143. https://doi.org/10.1093/cje/27.1.123

[86] Zahra, S.A. (1993) New Product Innovation in Established Companies: Associations with Industry and Strategy Variables. Entrepreneurship Theory and Practice, 18, 47-69. https://doi.org/10.1177/104225879401800203

[87] Blundell, R., Griffith, R. and Van Reenen, J. (1999) Market Share, Market Value and Innovation in a Panel of British Manufacturing Firms. Review of Economic Studies, 66, 529-554. https://doi.org/10.1111/1467-937X.00097

[88] Smolny, W. (2003) Determinants of Innovation Behaviour and Investment Estimates for West-German Manufacturing Firms. Economics of Innovation and NeW Technology, 12, 449-463. https://doi.org/10.1080/1043859022000029230

[89] Debackere, K., Clarysse, B. and Rappa, M.A. (1996) Dismantling the Ivory Tower: The Influence of Networks on Innovative Output in Emerging Technologies. Technological Forecasting and Social Change, 53, 139-154. https://doi.org/10.1016/S0040-1625(96)00036-4

[90] Beneito, P. (2003) Choosing among Alternative Technological Strategies: An Empirical Analysis of Formal Sources of Innovation. Research Policy, 32, 693-713. https://doi.org/10.1016/S0048-7333(02)00079-3

[91] Crepon, B., Duguet, E. and Mairesse, J. (1998) Research, Innovation and Productivity: An Econometric Analysis at the Firm Level. Economics of Innovation and New Technology, 7, 115-158. https://doi.org/10.1080/10438599800000031

[92] Sternberg, R. and Arndt, O. (2001) The Firm or the Region: What Determines the Innovation Behaviour of European Firms? Economic Geography, 77, 364-382. https://doi.org/10.2307/3594106

[93] Romijn, H. and Albaladejo, M. (2002) Determinants of Innovation Capability in Small Electronics and Software Firms in Southeast England. Research Policy, 31, 1053-1067. https://doi.org/10.1016/S0048-7333(01)00176-7

[94] Kaufmann, A. and Todtling, F. (2001) Science-Industry Interaction in the Process of Innovation: The Importance of Boundary-Crossing between Systems. Research Policy, 30, 791-804. https://doi.org/10.1016/S0048-7333(00)00118-9 
[95] Blind, K. and Grupp, H. (1999) Interdependencies between the Science and Technology Infrastructure and Innovation Activities in German Regions: Empirical Findings and Policy Consequences. Research Policy, 28, 451-468. https://doi.org/10.1016/S0048-7333(99)00007-4

[96] Beugelsdijk, S. and Cornet, M. (2002) "A Far Friend Is Worth More than a Good Neighbor": Proximity and Innovation in a Small Country. Journal of Management and Governance, 6, 169-188. https://doi.org/10.1023/A:1015775321949

[97] Keizer, J.A., Dijkstra, L. and Halman, J.I.M. (2002) Explaining Innovative Efforts of SMEs. An Exploratory Survey among SMEs in the Mechanical and Electrical Engineering Sector in the Netherlands. Technovation, 22, 1-13. https://doi.org/10.1016/S0166-4972(00)00091-2

[98] Morris, M.H., Avila, R.A. and Allen, J. (1993) Individualism and the Modern Corporation: Implications for Innovation and Entrepreneurship. Journal of Management, 19, 595-612. https://doi.org/10.1177/014920639301900305

[99] Rhyne, L.C., Teagarden, M.B. and Van den Panhuyzen, W. (2002) Technology-Based Competitive Strategies. The Relationship of Cultural Dimensions to New Product Innovation. The Journal of High Technology Management Research, 13, 249-277. https://doi.org/10.1016/S1047-8310(02)00047-0

[100] Shane, S. (1993) Cultural Influences on National Rates of Innovation. Journal of Business Venturing, 8, 59-73. https://doi.org/10.1016/0883-9026(93)90011-S

[101] Lin, Y. and Forrest, B. (2011) Systemic Structure behind Human Organizations: From Civilizations to Individuals. Springer, New York.

[102] Fritsch, M. and Meschede, M. (2001) Product Innovation, Process Innovation, and Size. Review of Industrial Organization, 19, 335-350.

https://doi.org/10.1023/A:1011856020135

[103] Koschatzky, K., Bross, U. and Stanovnik, P. (2001) Development and Innovation Potential in the Slovene Manufacturing Industry: Analysis of an Industrial Innovation Survey. Technovation, 21, 311-324. https://doi.org/10.1016/S0166-4972(00)00050-X

[104] Landry, R., Amara, N. and Lamari, M. (2002) Does Social Capital Determine Innovation? To What Extent? Technological Forecasting and Social Change, 69, 681-701. https://doi.org/10.1016/S0040-1625(01)00170-6

[105] Freel, M.S. (2003) Sectoral Patterns of Small Firm Innovation, Networking and Proximity. Research Policy, 32, 751-770. https://doi.org/10.1016/S0048-7333(02)00084-7

[106] Ritter, T. and Gemunden, H.G. (2003) Network Competence: Its Impact on Innovation Success and Its Antecedents. Journal of Business Research, 56, 745-755. https://doi.org/10.1016/S0148-2963(01)00259-4

[107] Dosi, G., Freeman, C., Nelson, R., Silverberg, G. and Soete, L. (1988) Technical Change and Economic Theory. Pinter, London.

[108] Kline, S.J. and Rosenberg, N. (1986) An Overview of Innovation. In: Landau, R. and Rosenberg, N., Eds., The Positive Sum Strategy: Harnessing Technology for Economic Growth, National Academy Press, Washington DC, 275-307.

[109] Malecki, E.J. (1997) Technology and Economic Development. Addison-Wesley Longman, Harlow.

[110] Ahuja, G. and Katila, R. (2001) Technological Acquisitions and the Innovation Performance of Acquiring Firms: A Longitudinal Study. Strategic Management Journal, 22, 197-220. https://doi.org/10.1002/smj.157 
[111] Love, J.H. and Roper, S. (2001) Location and Network Effects on Innovation Success: Evidence for UK. German and Irish Manufacturing Plants. Research Policy, 30, 313-332. https://doi.org/10.1016/S0048-7333(00)00098-6

[112] Souitaris, V. (2001) External Communication Determinants of Innovation in the Context of a Newly Industrialised Country: A Comparison of Objective and Perceptual Results from Greece. Technovation, 21, 25-34. https://doi.org/10.1016/S0166-4972(00)00014-6

[113] Coombs, R. and Tomlinson, M. (1998) Patterns in UK Company Innovation Styles: New Evidence from the CBI Innovation Trends Survey. Technology Analysis and Strategic Management, 10, 295-310. https://doi.org/10.1080/09537329808524318

[114] Lanjouw, J.O. and Mody, A. (1996) Innovation and the International Diffusion of Environmentally Responsive Technology. Research Policy, 25, 549-571.

https://doi.org/10.1016/0048-7333(95)00853-5

[115] Oyelaran-Oyeyinka, B., Laditan, G.O.A. and Esubiyi, A.O. (1996) Industrial Innovation in Sub-Saharan Africa: The Manufacturing Sector in Nigeria. Research Policy, 25, 1081-1096. https://doi.org/10.1016/S0048-7333(96)00889-X

[116] Czichos, H., Saito, T. and Smith, L. (2011) Springer Handbook of Metrology and Testing. 2nd Edition, Springer, New York. https://doi.org/10.1007/978-3-642-16641-9

[117] Liu, S.F. and Lin, Y. (2006) Grey Information: Theory and Practical Applications. Springer, London.

[118] Forrest, Y.L.J. and Tallapally, P. (2017) Fast Changing Markets, Transient Competitive Advantages and Key Organizational Element for Firms. Proceedings of 2017 NABET Annual Conference, State College, 26-27 October 2017, 80-93.

[119] Kuhn, T. (1962) The Structure of Scientific Revolutions. University of Chicago Press, Chicago. 